\title{
A formação de professores como possibilidade de (trans)formação social: uma análise baseada em estudos bibliográficos
}

Teacher education as a possibility of social (trans)formation: an analysis based on bibliographic studies

La formación del profesorado como posibilidad de (trans) formación social: un análisis a partir de estudios bibliográficos

Dieison Prestes da Silveira ORCID: https://orcid.org/0000-0002-8446-4157 Universidade Federal do Paraná, Brasil

E-mail: dieisonprestes@gmail.com

Joselia Cristina Siqueira da Silva

ORCID: https://orcid.org/0000-0003-2448-9886

Universidade Federal do Paraná, Brasil

E-mail: jcristinaquimica@gmail.com

Denise da Costa Dias Scheffer

ORCID: https://orcid.org/0000-0002-1755-542X

Universidade de Cruz Alta, Brasil

E-mail: dcdscheffer@gmail.com

Régis dos Santos Martines

ORCID: https://orcid.org/0000-0003-2469-3457

Universidade Federal de Santa Maria, Brasil

E-mail: regissmartines@gmail.com

Adriele Prestes da Silveira

ORCID: https://orcid.org/0000-0002-5157-7112 Instituto Federal Farroupilha, Brasil

E-mail: adrieleprestesdasilveira@gmail.com

Deivid Jonas Silva da Veiga

ORCID: https://orcid.org/0000-0002-1625-0560

Universidade de Cruz Alta, Brasil

E-mail: deividveiga96@gmail.com

Merian Souza da Penha Jacob

ORCID: https://orcid.org/0000-0002-3557-5176

Universidade Federal do Espírito Santo, Brasil

E-mail: merian_souza@ hotmail.com

Karla Silva Bisi Bianchi

ORCID: https://orcid.org/0000-0002-8419-3625

Universidade Federal do Espírito Santo, Brasil

E-mail: karla.bisi@hotmail.com

Antonio Carlos Vieira Machado

ORCID: https://orcid.org/0000-0003-2381-7593

Pontifícia Universidade Católica de Goiás, Brasil

E-mail: antoniocvm13@hotmail.com

Luciana de Almeida Silva Drago

ORCID: https://orcid.org/0000-0001-8862-7841

Faculdade da Região dos Lagos, Brasil

E-mail: lucianaalmeidasilvadrago@gmail.com

Janaria Candeias de Oliveira Carminati

ORCID: https://orcid.org/0000-0003-0468-7391

Universidade Federal do Espírito Santo, Brasil

E-mail: janarya.candeia@ hotmail.com

\section{Resumo}

O processo formativo de um docente requer diferentes vivências e experiência, tendo o diálogo e o contexto dos estudantes como elementos basilares para a construção de novos conhecimentos. É neste caminho de debates, provocações e discussões que o presente artigo se constitui, sinalizando caminhos, possibilidades e epistemes no contexto formativo de professores, com vistas a contribuir com o processo de (trans)formação social dos alunos. Pensando nestas inquietações, o presente artigo tem o objetivo de analisar a formação de professores, atentando para a 
diversidade de saberes, vivências e experiências presentes no meio educacional e que perfazem os saberes docentes. Em se tratando de aspectos metodológicos, pode-se dizer que o presente estudo apresenta uma abordagem do tipo qualitativa, com foco em uma pesquisa bibliográfica, cuja análise dos dados se deu por meio da Análise Textual Discursiva, com a criação de categorias emergentes. Pode-se dizer que a formação de professores precisa inserir a realidade dos estudantes na dinâmica ensino e aprendizagem, sinalizando caminhos para uma formação humana, crítica e emancipatória, atentando para a pluralidade de saberes, vivências e identidades que se fazem presentes no meio sociocultural. Da mesma forma, vê-se imprescindível uma formação permanente de docentes, com vistas a contribuir com os debates envolvendo ciência, cultura, política, economia, meio ambiente e sociedade, discutindo ideias e posicionamentos hegemônicos e que acabam alienando os sujeitos.

Palavras-chave: Formação de professores; Ensino e aprendizagem; Separadas; Experiências; Debates.

\begin{abstract}
The training process of a teacher requires different experiences and experiences, with the students' dialogue and context as basic elements for the construction of new knowledge. It is in this path of debates, provocations and discussions that this article is constituted, signaling paths, possibilities and epistemes in the educational context of teachers, with a view to contributing to the process of social (trans)formation of students. Considering these concerns, this article aims to analyze the training of teachers, paying attention to the diversity of knowledge, experiences and experiences present in the educational environment and that make up the knowledge of teachers. In terms of methodological aspects, it can be said that the present study presents a qualitative approach, focusing on a bibliographical research, whose data analysis took place through Discursive Textual Analysis, with the creation of emerging categories. It can be said that teacher education needs to insert the students' reality into the teaching and learning dynamics, signaling paths for human, critical and emancipatory education, paying attention to the plurality of knowledge, experiences and identities that are present in the sociocultural environment. Likewise, permanent teacher training is essential, with a view to contributing to debates involving science, culture, politics, economy, environment and society, discussing hegemonic ideas and positions that end up alienating subjects.
\end{abstract}

Keywords: Teacher training; Teaching and learning; Experiences; Debates.

\title{
Resumen
}

El proceso de formación de un docente requiere diferentes vivencias y vivencias, con el diálogo y el contexto de los estudiantes como elementos básicos para la construcción de nuevos conocimientos. Es en este camino de debates, provocaciones y discusiones donde se constituye este artículo, señalando caminos, posibilidades y epistemes en el contexto educativo de los docentes, con miras a contribuir al proceso de (trans) formación social de los estudiantes. Teniendo en cuenta estas inquietudes, este artículo tiene como objetivo analizar la formación de los docentes, prestando atención a la diversidad de conocimientos, experiencias y vivencias presentes en el ámbito educativo y que configuran los conocimientos de los docentes. En cuanto a los aspectos metodológicos, se puede decir que el presente estudio presenta un abordaje cualitativo, enfocándose en una investigación bibliográfica, cuyo análisis de datos se realizó a través del Análisis Textual Discursivo, con la creación de categorías emergentes. Se puede decir que la formación del profesorado necesita insertar la realidad de los estudiantes en las dinámicas de enseñanza y aprendizaje, señalando caminos para la educación humana, crítica y emancipadora, prestando atención a la pluralidad de saberes, experiencias e identidades presentes en el entorno sociocultural. Asimismo, la formación permanente del profesorado es fundamental, con miras a contribuir a debates que involucren ciencia, cultura, política, economía, medio ambiente y sociedad, discutiendo ideas y posiciones hegemónicas que acaben por alienar a los sujetos.

Palabras clave: Formación docente; Enseñando y aprendiendo; Experiencias; Debates.

\section{Introdução}

A profissão docente exige inúmeras habilidades, haja vista que há uma multiplicidade de sujeitos dentro dos ambientes educacionais, oriundos de diversos contextos socioculturais. Cabe dizer que nos espaços escolares, alunos e professores trocam saberes, refletem sobre as questões emergentes e constroem de forma conjunta o conhecimento. Da mesma forma, dialogam, criam situações problemas e, ainda, buscam respostas aos anseios e prerrogativas que se apresentam em suas realidades sociais.

No dia a dia de um docente, são muitos os desafios a serem enfrentados, como por exemplo, indisciplina, conflitos sociais, bullying, violência e até mesmo casos de evasão escolar, necessitando cada vez mais de uma formação de professores para além da abordagem de conceitos teóricos e metodológicos. O processo formativo de um docente precisa preparar os professores para as adversidades sociais, atentando para a polissemia de vivências e experiências que se apresentam. Da 
mesma forma, há necessidade de formar sujeitos para atuarem com autonomia, responsabilidade e criticidade na sociedade, sendo ator social, contribuindo com o contexto da sua realidade e dos demais espaços de convívio.

A formação de professores, inicial, continuada e/ou permanente se apresenta como um lócus investigativo fértil para novas pesquisas, balizando para a diversidade de saberes e práticas socioculturais imersas no contexto educacional. Pode-se dizer que dentro dos espaços escolares, alunos e professores precisam ter o diálogo e o conhecimento como eixo formativo, sinalizando para um debate epistêmico acerca da cultura, política, meio ambiente, economia e tantas outras temáticas emergentes.

O processo de ensino e aprendizagem, sendo uma troca de conhecimentos, precisa partir do contexto em que os alunos e a comunidade escolar estão inseridos, objetivando a construção de práticas e ações em prol do desenvolvimento local. Por meio de estudos e discussões referentes ao dia a dia dos alunos é que se pode transformar a realidade dos sujeitos, haja vista que o ensino se torna contextualizado, dialógico e com condições para mudanças significativas no modo de pensar e agir. No mesmo sentido, pode-se dizer que a educação precisa ser vista como uma forma de libertar os indivíduos das ideias hegemônicas e alienadoras que se fazem presente, culminando na formação de sujeitos críticos, autônomos e reflexivos na sociedade (Freire, 2001).

A educação, sendo uma forma de intervenção social, deve permitir o desenvolvimento e o processo formativo dos sujeitos com características cidadãs, os quais sabem atuar de forma responsável na sociedade, questionando e problematizando a cultura, economia, política e meio ambiente, tornando-se atores sociais. Sabe-se que cada estudante é único e apresenta especificidades, portanto, o professor deve pensar em metodologias e recursos didáticos-pedagógicos para inserir os alunos nas aulas, colaborando com o processo de ensino e aprendizagem. Ainda, cabe salientar que o professor precisa levar em consideração as condições da comunidade escolar e trabalhar para dinamizar o conhecimento e contribuir com uma qualidade de vida dos indivíduos, pautando a abordagem de conteúdos curriculares de forma contextualizada com a realidade dos estudantes, tendo o diálogo e as múltiplas interações entre sujeitos como princípios básicos para o processo de ensino e aprendizagem.

$\mathrm{Na}$ atualidade, com a pandemia provocada pela COVID-19, a formação de professores, os saberes docentes e o ensino e aprendizagem se tornaram elementos importantes na busca por uma educação crítica, reflexiva e com reflexos na sociedade. Em se tratando da formação de professores, há de se considerar as especificidades na mudança repentina do ensino presencial para o remoto. O processo de ensino e aprendizagem depende quase que exclusivamente do uso da Tecnologia da Informação e Comunicação, com especial destaque ao celular, computador e internet. Entretanto, cabe destacar que existem inúmeras desigualdades sociais, o que dificulta o acesso aos conhecimentos de muitos jovens estudantes, pois não apresentam acesso à internet, nem mesmo tem condições de adquirir um aparelho celular e/ou computador. É neste percurso de desafios, adaptações e incertezas que alunos e professores buscam aprender e trocar saberes, tendo o conhecimento e o processo de humanização como pontos de partidas para futuras (trans)formações no modo de pensar e agir na sociedade.

Pensando nisso, justifica-se a relevância de ampliar as discussões envolvendo a formação de professores, haja vista que esta ação educativa pode e precisa modificar o modo de pensar dos cidadãos, buscando mitigar o alienamento social, ideológico e político que acaba intensificando as desigualdades e promovendo conflitos. Inserir os estudantes no conhecimento, consiste em mostrar caminhos e possibilidades, embasados na ciência, articulando vivências, experiências e conhecimento científico na busca pela emancipação social. É neste percurso de debates, provocações e discussões que o presente artigo se constitui, sinalizando caminhos e possibilidades no contexto formativo de professores, com vistas a contribuir com o processo de (trans)formação social dos estudantes. Pensando nestas inquietações, o presente artigo tem o objetivo de analisar o processo formativo de um docente, atentando para a diversidade de saberes, vivências e experiências presentes no meio educacional e que perfazem o dia a dia docente. 


\section{Metodologia}

Em se tratando de processos e caminhos metodológicos, Fachin (2003) explicita que toda a pesquisa cientifica precisa de um rigor metodológico, visando a obtenção dos dados. Na visão de Severino (2007, p. 15), as pesquisas científicas têm caráter pessoal e acabam apresentando:

[...] uma dimensão social, o que confere o seu sentido político. Esta exigência de uma significação política englobante, implica que, antes de buscar-se um objeto de pesquisa, o pós-graduando pesquisador já deve ter pensado o mundo, indagando-se criticamente a respeito de sua situação, bem como da situação de seu projeto e de seu trabalho nas tramas políticas de qualquer realidade social (Severino, 2007, p. 15).

Em relação a abordagem metodológica desta investigação, pode-se dizer que a pesquisa é do tipo qualitativa. Na visão de Minayo (2012), principalmente no campo das ciências sociais, as pesquisas denominadas qualitativas buscam compreensões de fatos e circunstâncias que se fazem presentes na sociedade. É nesta proposição que a presente pesquisa se insere, haja vista que discute questões voltadas a formação de professores, ensino e aprendizagem, sinalizando para novos debates acerca da polissemia de saberes, vivências e experiências que se fazem presentes nos ambientes educacionais.

Ainda sobre a metodologia, cabe dizer que ocorreu uma pesquisa bibliográfica, sendo utilizados periódicos, artigos, livros, teses e dissertações que possam fornecer subsídios no tocante a formação de professores, as trocas de saberes, vivências e experiências na contemporaneidade. Pensando nas pesquisas bibliográficas, Gil (2002) comenta que toda a pesquisa científica necessita de uma investigação bibliográfica, pois assim, consegue-se compreender o que está sendo discutido e o que há de atual no campo científico. As pesquisas bibliográficas fornecem um conglomerado de informações e dados que servem como uma atualização de determinadas temáticas, haja vista que comumente novas pesquisas são desenvolvidas e novos dados são apresentados. Ainda, explicitando a relevância das pesquisas bibliográficas, Severino (2007, p. 122) relata que consiste em um:

[...] registro disponível, decorrente de pesquisas anteriores, em documentos impressos, como livros, artigos, teses etc. Utilizam-se dados de categorias teóricas já trabalhadas por outros pesquisadores e devidamente registrados. Os textos tornam-se fontes dos temas a serem pesquisados. O pesquisador trabalha a partir de contribuições dos autores dos estudos analíticos constantes dos textos.

Para a análise dos dados desta pesquisa, optou-se pela Análise Textual Discursiva que, de acordo com Moraes e Galiazzi (2006), começa com a unitarização dos dados em subcategorias, tendo sempre o olhar empírico do pesquisador. Moraes e Galiazzi (2006, p. 120) abordam que "A utilização da análise textual discursiva tem mostrado tratar-se de uma ferramenta aberta, exigindo dos usuários aprender a conviver com uma abordagem que exige constantemente a (re)construção de caminhos. No mesmo sentido, os autores enfatizam que a Análise Textual Discursiva permite a categorização dos dados, podendo ser categoria a priori ou emergente. No caso deste estudo, utilizou-se a categoria emergente, pois o pesquisador tem a autonomia de (re)criar e remodelar, conforme os dados vão sendo apresentados (Moraes; Galiazzi, 2006).

\section{Formação de Professores: Caminhos, Possibilidades e Epistemes}

A formação de professores precisa ser vista como um processo contínuo e que necessita de constantes problematizações, pois envolve conhecimentos sociais, culturais, ambientais, políticos e econômicos e, ainda, apresenta como centro do processo formativo, seres humanos com distintas realidades. Silveira et al. (2020, p. 38) relatam que:

A formação de professores é uma temática que necessita de constantes diálogos, debates e provocações, visto que 
insere uma diversidade de saberes, vivências e experiências. Cada professor apresenta a sua didática, bem como a sua forma de mediar o conhecimento, ou seja, cada docente apresenta a sua identidade dentro do ambiente escolar, oriunda do seu processo de formação.

No atual contexto mundial, com a pandemia da COVID-19, muito se discute a formação de professores, principalmente porque ocorreu uma transição repentina do ensino presencial para o remoto. Tupan, Nunes, Mincache e Souza (2021) comentam que dentre as diversas áreas do conhecimento, as disciplinas das ciências exatas acabaram sofrendo um impacto relativamente grande, tendo em vista a necessidade do uso do quadro negro para exemplificar e expor as equações e resolução de exercícios. Nesse processo de mudanças, deve-se considerar as múltiplas tarefas baseadas no ensino remoto, como por exemplo, preparar as aulas, postar no Ambiente Virtual de Aprendizagem (AVA), corrigir exercícios, verificar plágio, mediar o conhecimento por meio de vídeo aulas e, ainda, aprender a manusear as Tecnologias da Informação e Comunicação (TIC's). Observa-se um acúmulo de atividades por parte dos professores, devendo uma atenção especial ao bemestar físico e o cansaço mental. Em relação aos alunos, com o ensino remoto e o contato com o professor de forma virtual, ocorrem situações de pouca participação e interesse, bem como falta de reciprocidade, uma vez que o professor não está diretamente observando os estudantes.

Em consonância com o exposto acima, pensar na formação de professores, traz consigo provocações acerca da formação inicial e os estágios, pois o ensino remoto foi/é uma realidade e, talvez, seja algo a ser instituído em outros ambientes educacionais. Silveira et al (2021, p. 6) explicitam que:

O atual período vivenciado pela população, devido a pandemia provocada pelo Novo Coronavírus e os debates sociopolíticos, traz consigo provocações necessárias, como por exemplo, o professor é uma figura que precisa de melhores condições de trabalho, respeito e valorização, visto que ele contribui na formação dos sujeitos para as vivências em sociedade. Ainda, o professor deve atuar de forma a mitigar casos de alienação social e ideológica e, os estágios na formação de professores, ao inserirem os estudantes de licenciaturas nos ambientes educacionais, permitem novos olhares e debates no processo de ensino e aprendizagem, atentando para as práticas sociais e educacionais.

$\mathrm{Na}$ contemporaneidade, sabe-se que existe uma multiplicidade de saberes e, nesta perspectiva, a formação de professores se insere como uma possibilidade de trocar conhecimentos e permitir novas (trans)formações na vida dos estudantes. Silva e Lorenzetti (2020, p. 3) comentam "Não cabe somente ao professor esse desafio, mas ao sistema educacional como um todo, o qual deve proporcionar condições materiais, profissionais e intelectuais capazes de assegurar aos professores uma atuação educativa mais efetiva". Noutras palavras, é preciso um engajamento da comunidade e dos órgãos públicos competentes, visando a efetividade dos direitos a uma educação de qualidade e que permita mudanças no modo de pensar e agir na sociedade.

Ao se pensar no processo formativo de um docente, deve-se pensar na relevância da articulação entre teoria e prática, perfazendo as práxis na educação. Por meio de momentos dialógicos e práticos, estudantes e professores precisam compreender que o contexto em que a comunidade está inserida se torna um lócus investigativo, capaz de contribuir com a realidade dos estudantes e possibilitar o aperfeiçoamento dos saberes docentes. Tardif (2011) destaca que os saberes docentes são aqueles vivenciados diariamente, por meio das inter-relações entre alunos, professores e a comunidade local. Conforme o professor dialoga com os alunos, ele aprende algo novo e contextualiza o conhecimento, inserindo questões vivenciais dos estudantes a dinâmica aula.

A contextualização é uma proposição fundamental quando se discute a formação de professores, seja ela inicial, continuada e/ou permanente. Por meio de um ensino contextualizado e dialógico ocorre o processo de formação para a cidadania, envolvendo atitudes e valores que favoreçam no (con)viver em sociedade. Vaine e Lorenzetti (2020, p. 297) consideram que "[...] a prática docente requer uma formação permanente", ou seja, o processo formativo de um professor 
precisa ser constante, principalmente, devido a diversidade de novos saberes e a ampliação da cultura científica.

Este processo de construção identitária e inserção da cultura científica, precisa começar na formação inicial, inserindo os estudantes de licenciaturas nos ambientes escolares, perfazendo conexões entre as Instituições de Ensino Superior (IES) e as escolas. Nesse sentido, vê-se imprescindível a criação de políticas públicas e projetos que permeiam o ensino, a pesquisa e a extensão, fomentando e potencializando o debate envolto as temáticas sociais, políticas, ambientais, culturais e educacionais, com vistas a institucionalizar o conhecimento científico nos mais variados espaços da sociedade. Diante destas prerrogativas, André (2017, p. 5) afirma que:

[...] cabe aos gestores das políticas públicas desenvolver programas ou criar condições para que as escolas possam desenvolver projetos que favoreçam a transição do estudante a professor. É importante que essas políticas sejam especialmente desenhadas para a inserção profissional, momento que se diferencia da formação inicial e continuada, pelas suas peculiaridades, de fase de transição, de integração na cultura docente, de inserção na cultura escolar, de aprendizagem dos códigos e das normas da profissão.

Para Delizoicov, Angotti e Pernambuco (2011), é preciso uma formação de professores que reconheça que o ensino deixou de ser para poucos e, ainda, deve-se observar que o ensino e a aprendizagem são processos indispensáveis para a transformação de um sujeito. Na mesma linha de pensamento, Colombo Junior et al., (2012) afirmam que não se deve pensar que o ensino, principalmente o Ensino de Ciências, se deve basear em saber e ler e escrever. Precisa-se entender que a abordagem de conhecimentos necessita de múltiplas relações com a sociedade, com as vivências grupais, com o diálogo, com as trocas de experiências e com o convívio entre sujeitos.

A formação de professores precisa formar estudantes autônomos, reflexivos e engajados com as questões mundiais. Discutir a formação de professores consiste em emponderar os alunos a um discurso sábio, crítico e que inter-relacione questões teóricas com momentos práticos, com vistas a uma tomada de decisão no meio sociocultural. Diante desta problemática, observa-se que a formação de professores - inicial, continuada e/ou permanente - deve ir além de momentos memorísticos e conteudistas, os quais pouco relacionam com um contexto interdisciplinar, emancipatório e formativo (Silva; Lorenzetti, 2020).

O processo formativo de um docente precisa engajar os sujeitos para a construção de um pensamento coletivo em prol das diferenças, das desigualdades sociais, capitalistas, ambientais, culturais e econômicas. Por meio do processo formativo de professores, ocorre a abordagem de metodologias de ensino diversificadas que promovem o despertar dos estudantes pela busca de respostas aos problemas presentes na sua comunidade. Isso contribui com a formação de cidadãos ativos na sociedade, principalmente debatendo as ideias hegemônicas e alienadoras que se fazem presentes e que acabam distanciando os estudantes do conhecimento científico.

\section{Formação de Professores na Atualidade: Articulações e Contextualizações Necessárias}

No atual contexto sociopolítico e educacional existe uma diversidade de Fake News, movimentos antivacinas, contexto de Pós-verdade, pseudociência e negacionismo que precisam ser discutidos e sinalizados como movimentos que acabam desconstruindo a ideia de educação democrática e libertadora. Freire (2001) afirma que por meio de uma educação emancipatória, democrática e libertadora é possível formar sujeitos críticos, autônomos e responsáveis para uma tomada de decisão na sociedade. É nesta perspectiva de diálogo que o presente capítulo se estrutura, balizando caminhos, possibilidades e epistemes para o processo de (trans)formação social.

Para o processo de (trans)formação social de um sujeito, deve-se pensar, primeiramente, que "A formação de indivíduos faz parte da premissa da educação, ela está presente no cotidiano escolar, na vida em sociedade e nas relações 
familiares [...]" (Scheffer, 2021, p. 3-4). Da mesma forma, "Com o desenvolvimento da educação, tornou-se evidente a necessidade de desenvolver no educando, a capacidade de interagir criticamente com as pessoas em seu meio" (Siqueira et al., 2021, p. 2). Nesse sentido, discutir as temáticas que emergem na sociedade, com enfoque na formação de professores, consiste em criar condições de desenvolver uma prática docente crítica, capaz de problematizar ações e (des)construir conceitos. Freire (2001, p. 42-43) explicita que:

[...] a prática docente crítica, implicante do pensar certo, envolve o movimento dinâmico, dialético, entre o fazer e o pensar sobre o fazer [...]. O que se precisa é possibilitar que, voltando-se sobre si mesma, através da reflexão sobre a prática, a curiosidade ingênua, percebendo-se como tal, se vá tornando crítica [...]. A prática docente crítica, implicante do pensar certo, envolve o movimento dinâmico, entre o fazer e o pensar sobre o fazer.

Pensar em formação de professores, consiste em problematizar o currículo, rever as metodologias e recursos didáticopedagógicos utilizadas e, acima de tudo, inserir os estudantes no diálogo construtivo com a sociedade. Silveira e Golle (2019, p. 19) afirmam que "É nas escolas que o docente em formação inicial irá se deparar com circunstâncias voltadas ao cotidiano de sua profissão". Noutras palavras, é dentro dos ambientes escolares que o professor irá constituir a sua identidade, bem como aperfeiçoar seus saberes e articular os conhecimentos curriculares com a realidade dos estudantes.

Com a pandemia da COVID-19, as desigualdades sociais, econômicas, políticas e culturais foram explicitadas. Nesse contexto, o processo formativo de um sujeito precisa levar em consideração a diversidade sociocultural, portanto, precisa-se intensificar o diálogo e promover encontros formativos multidisciplinares, que valorizem as diferenças e (re)pense as questões contemporâneas. Guedes et al. (2021, p. 8) explicitam é “[...] possível desenvolver uma formação multidisciplinar, considerando que em todas as áreas deve-se praticar uma educação antirracista que valorize a história, a cultura e a ancestralidade dos povos negros e indígenas e seu legado na formação socioculturais de nosso país, mas que, devido ao racismo estrutural, sofreram e ainda sofrem apagamentos socioculturais através da invisibilidade e negação de seu legado". É neste caminho de entraves, dilemas e mazelas que a formação de professores e junto a ela a formação de sujeitos críticos, deve ser palco de debates e diálogos. Formar um indivíduo consiste em articular conhecimentos teórico-práticos, perfazendo as práxis no contexto socioeducacional, instigando o desenvolvimento e a formação de atores sociais, comprometidos em atuar na sociedade de forma a mitigar as desigualdades e os bloqueios sociais, promovidos pela cultura, política e tantas outras arestas dicotômicas.

O ensino e aprendizagem precisa pautar-se no diálogo e em momentos de exposição de ideias, ou seja, as aulas devem permitir as trocas conhecimentos, contextualizando os conteúdos curriculares e aproximando os alunos do saber científico. Por meio destes processos, o professor acaba adquirindo novos saberes, pois, conforme explicita Tardif (2011), os saberes docentes estão sempre em construção, uma vez que são oriundos de diferentes contextos socioeducacionais. É nesta conjuntura de vivências, abordagens epistemológicas, experiências diárias e movimentos dialógicos que o professor acaba compreendendo a relevância do exercício da profissão docente, sendo uma ação de troca constante de conhecimentos.

Pensar na formação de professores, implica em rever as condições estabelecidas para que o professor exerça sua profissão de forma a contribuir com o desenvolvimento crítico e reflexivo dos estudantes. As diversas políticas de silenciamento no campo da educação acabam (inter)ferindo no processo construtivo dos sujeitos para uma tomada de decisão sábia na sociedade. Diante disso, observa-se a relevância de uma formação permanente de docentes, os quais, de forma engajada, estimulam os alunos a buscarem novos conhecimentos e se tornarem ativos na sociedade. Na visão de Perrenoud e Thurler (2002, p. 170), “O professor-educador deve assumir responsabilidade ética de ser um agente de mudanças em seu ambiente de trabalho, transformando-se em um multiplicador de novas ideias". Por meio desta afirmação, pode-se perceber que 
o professor-educador apresenta em sua essência a responsabilidade de direcionar os estudantes para um mundo de descobertas, direcionando os estudantes para as (con)vivências sociais.

\section{Conclusão}

O presente estudo trouxe consigo provocações necessárias, discutindo e analisando o processo formativo de um docente. São diversas vivências, experiências e trocas de saberes que constituem o dia a dia de um professor, visto que dentro dos ambientes educacionais há uma pluralidade de sujeitos com distintas identidades. É neste percurso formativo que o contexto dos alunos precisa fazer parte da dinâmica aula, sendo o professor um sujeito problematizador, sinalizando possibilidades de desenvolvimento pessoal e profissional aos seus estudantes.

O contexto em que os estudantes estão inseridos se torna elemento basilar quando se pensa em formação de professores, pois o docente precisa pensar na sua abordagem teórico-metodológica, atentando para as especificidades de seus estudantes. O diálogo e as inter-relações sociais precisam estar presentes em sala de aula, motivando a construção de um debate sobre as temáticas emergentes e hegemônicas que muitas vezes se fazem presentes. No mesmo sentido, cabe ao professor desmistificar Fake News, negacionismos e tantas outras entraves que acometem a sociedade. Quando se discute formação de professores, discute-se também as condições estabelecidas pelos docentes para o processo de mediação do conhecimento, bem como a responsabilidade que a profissão apresenta - de formar sujeitos autônomos, críticos, reflexivos e com conhecimentos para uma atuação ativa na sociedade.

Como sugestão de novas pesquisas na área, reiteramos a necessidade de estudos envolvendo a formação de professores, pois cada docente apresenta a sua episteme e a sua forma de mediar conhecimento. Adicionalmente, destacamos que os anos de 2020 e 2021 trouxeram provocações relevantes acerca do ensino remoto, das Fake News, contexto de Pósverdade, negacionismo, desvalorização da ciência e Políticas Públicas de silenciamento. Diante destas prerrogativas, o campo científico necessita de novas pesquisas, novos debates e discussões profícuas, críticas e com reflexos diretos na forma de pensar e agir na sociedade.

\section{Agradecimentos}

Agradeço a Coordenação de Aperfeiçoamento de Pessoal de Nível Superior - CAPES, pela bolsa de Pesquisa em nível de doutorado. Por meio deste fomento ocorre um incentivo a pesquisa no Brasil, contribuindo com a divulgação e socialização do conhecimento nas mais variadas áreas do saber. Agradeço também aos demais autores que fazem parte deste trabalho e que contribuíram com a escrita deste artigo.

\section{Referências}

André, M. (2017). Inserção profissional de egressos de programas de iniciação à docência. Trabalho encomendado I Gt08 - formação de professores. $38^{\mathrm{a}}$ Reunião Nacional da Anped - 01 a 05 de outubro de 2017 - UFMA - São Luíz/MA. http://38reuniao.anped.org.br/sites/default/files/resources/program acao/trabalhoe ncom_38anped_2017_gt08i_textomarlyandre.pdf

Colombo, JR. P.C., Lourenço, A. B., Sasseron, L. H., \& Carvalho, A. M. P. (2012). Ensino de física nos anos iniciais: análise da argumentação na resolução de uma atividade de conhecimento físico. Investigação no ensino de ciências, 17, 489 - 507.

Delizoicov, D., Angotti, J. A. P., \& Pernambuco, M. M. C. A. (2011). Ensino de ciências: fundamentos e métodos. (4a ed.), Cortez.

Fachin, O. (2003). Fundamentos de metodologia. Saraiva.

Freire, P. (2001). Pedagogia da autonomia: saberes necessários à prática educativa. Paz e Terra.

Gil, A. C. (2002). Como elaborar projetos de pesquisa. Atlas.

Guedes, A. C. B., Ladislau, C. da S., Oliveira. A. C. de, Cardoso, T. X., Lobato, S. C. da S., \& Silva, F. N. L. da (2021). Ensino-aprendizagem em ambiente virtual: a experiência de docentes do Marajó, Brasil. Research, Society and Development, 10(11). 
Research, Society and Development, v. 10, n. 12, e312101220438, 2021

(CC BY 4.0) | ISSN 2525-3409 | DOI: http://dx.doi.org/10.33448/rsd-v10i12.20438

Minayo, M. C. de S. (Org.). (2012). Pesquisa social: teoria, método e criatividade. (32a ed.), Vozes.

Moraes, R., \& Galiazzi, M. do C. (2006). Análise Textual Discursiva: processo reconstrutivo de múltiplas faces. Ciência \& educação, 12(1), 117-128.

Perrenoud, P., \& Thurler, M. G. (2002). As competências para ensinar no século XXI: a formação dos professores e o desafio da avaliação. Artmed.

Scheffer, D. da C. D. (2021). Formação de professores: a didática acerca da abordagem dos direitos humanos pelo educador como formador de cidadãos. Research, Society and Development. 10, 1-7.

Severino, A. J. (2007). Metodologia do trabalho científico. (23a ed.), Cortez.

Silva, J. C. S. da., Bianco, G., Silveira, D. P. da., Gomes, R. V., Veiga, D. J. S. da., \& Serafim, L. Contribuições das atividades experimentais no processo de aprendizagem de soluções químicas. Research, Society and Development. 10(4),1-12.

Silva, V. R. da, \& Lorenzetti, L. (2020). A alfabetização científica nos anos iniciais: os indicadores evidenciados por meio de uma sequência didática. Educ. Pesqui., 46 .

Silveira, A. P. da, Silveira, D. P. da, Bassan, J. S., Silva, J. C. S. da, Scheffer, D. da D., \& Souza, V. S. (2021). O estágio de observação e suas contribuições no campo da educação: uma análise na formação de professores. Research, Society and Development, 10(40).

Silveira, D. P. da, Soares, E. G., Silva, J. C. S. da, \& Veiga, D. J. S. da (2020). Uma análise multidimensional na formação de professores: tecendo um novo olhar no campo da educação. Revista Di@logus, 9(3), 37-45.

Silveira, D. P., \& Golle, D. P. (2019). Confeccionando o seu relatório de estágio para cursos de licenciaturas: um enfoque nas ciências biológicas. Curitiba: Editora Appris.

Tardif, M. (2011). Saberes docentes e formação profissional. (12a ed.), vozes.

Tupan, L. F. da S., Nunes, G. C. de S., Mincache, A. J., \& Souza, A. O. de (2021). Perspectivas de professores de Física mediante o ensino remoto durante a pandemia de COVID-10. Reserch, Society and Development. 10(11).

Vaine, T. E., \& Lorenzetti, L. (2020). A cidade como espaço de formação permanente de professores: análise de um curso de formação continuada de professores a partir do enfoque CTS. Indagatio didactia, 12, (4) 